Article

\title{
Network Analysis of the Potential Role of DNA Methylation in the Relationship between Plasma Carotenoids and Lipid Profile
}

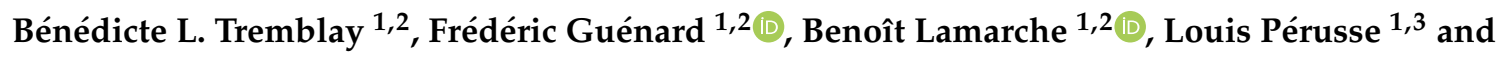 \\ Marie-Claude Vohl 1,2,*(D) \\ 1 Institute of Nutrition and Functional Foods (INAF), Laval University, 2440 Hochelaga Blvd, Quebec City, \\ QC G1V 0A6, Canada; benedicte-1.tremblay.1@ulaval.ca (B.L.T.); frederic.guenard@fsaa.ulaval.ca (F.G.); \\ benoit.lamarche@fsaa.ulaval.ca (B.L.); louis.perusse@kin.ulaval.ca (L.P.) \\ 2 School of Nutrition, Laval University, 2425 rue de l'Agriculture, Quebec City, QC G1V 0A6, Canada \\ 3 Department of Kinesiology, Laval University, 2300 rue de la Terrasse, Quebec City, QC G1V 0A6, Canada \\ * Correspondence: marie-claude.vohl@fsaa.ulaval.ca; Tel.: +1-418-656-2131 (ext. 404676)
}

Received: 17 April 2019; Accepted: 31 May 2019; Published: 4 June 2019

check for updates

\begin{abstract}
Variability in plasma carotenoids may be attributable to several factors including genetic variants and lipid profile. Until now, the impact of DNA methylation on this variability has not been widely studied. Weighted gene correlation network analysis (WGCNA) is a systems biology method used for finding gene clusters (modules) with highly correlated methylation levels and for relating them to phenotypic traits. The objective of the present study was to examine the role of DNA methylation in the relationship between plasma total carotenoid concentrations and lipid profile using WGCNA in 48 healthy subjects. Genome-wide DNA methylation levels of 20,687 out of 472,245 CpG sites in blood leukocytes were associated with total carotenoid concentrations. Using WGCNA, nine co-methylation modules were identified. A total of 2734 hub genes (17 unique top hub genes) were potentially related to lipid profile. This study provides evidence for the potential implications of gene co-methylation in the relationship between plasma carotenoids and lipid profile. Further studies and validation of the hub genes are needed.
\end{abstract}

Keywords: carotenoids; DNA methylation; french canadians; hub genes; lipid profile; WGCNA

\section{Introduction}

Cardiometabolic (CM) diseases comprise conditions ranging from insulin resistance and metabolic syndrome to cardiovascular disease and type-2 diabetes [1]. Healthy eating, including the consumption of fruits and vegetables, is associated with a favorable CM health [2]. Carotenoids, which are reliable biomarkers of fruit and vegetable intakes, are composed of hundreds of fat-soluble pigments [3]. However, six main carotenoids ( $\alpha$-carotene, $\beta$-carotene, $\beta$-cryptoxanthin, lutein, lycopene, and zeaxanthin) represent over $95 \%$ of total circulating carotenoids in human [4,5]. Variability among individuals in circulating carotenoids may be due to several factors, including age, sex, body weight, genetics, and lipid profile [3]. Lower circulating carotenoid concentrations are associated with lower plasma total cholesterol (TC), LDL-cholesterol (LDL-C), and HDL-cholesterol (HDL-C) concentrations [6]. Moreover, $\alpha$ - and $\beta$-carotene correlated with HDL-C and triglyceride (TG) concentrations [7], while $\beta$-crytoxanthin and zeaxanthin correlated with TG concentrations in a previous study by our group [8]. Thus, several studies have observed associations between circulating carotenoids and plasma lipid concentrations, which are both transported by lipoproteins [9].

Genetic variants have been shown to influence circulating carotenoid concentrations by causing differences in the absorption, assimilation, distribution, metabolism, and excretion of carotenoids [10-15]. 
Carotenoids and their derivatives (e.g., retinoid) have also been shown to modulate gene expression via several transcriptional systems [16]. However, very few studies have documented the relationship between carotenoids and DNA methylation, at least from a genome-wide viewpoint. In cell studies, lycopene had modest to null effects on DNA methylation of GSTP1, which is involved in prostate and breast cancers $[17,18]$. Moreover, a study of 165 overweight and obese subjects revealed an association between DNA methylation of $H E R V$-w and TNF $\alpha$ in blood leukocytes and dietary intakes of $\beta$-carotene and carotenoids [19]. Interestingly, the reported protective effects of high fruit and vegetable intake on age-related diseases (coronary heart disease, stroke, type-2 diabetes) may be mediated by the association between blood carotenoids levels and extrinsic epigenetic age acceleration, which is a measure of epigenetic age [20]. Thus, circulating carotenoids and dietary intakes of carotenoids seem to impact DNA methylation. Moreover, there is more and more evidence that DNA methylation plays a role in the regulation of blood lipid levels and lipid metabolism-linked phenotypes and diseases [21]. No previous study has considered the involvement of genome-wide DNA methylation levels in the association between plasma carotenoids and lipid profile. Weighted gene correlation network analysis (WGCNA) is a widely used systems biology approach designed for high dimensional data (i.e. gene expression, DNA methylation, metabolites etc.) [22]. It allows finding gene clusters (modules) with highly correlated DNA methylation levels, relating these modules to phenotypic traits, and identifying key hub genes within modules that are related to phenotypic traits [22].

The objective of the present study was to examine the role of DNA methylation in the relationship between plasma carotenoid concentrations and lipid profile using WGCNA in 48 healthy subjects. First, cytosine-phosphate-guanine (CpG) sites whose DNA methylation levels are associated with carotenoid concentrations were identified using linear regressions. Second, WGCNA was used to identify specific modules and key hub genes related to lipid profile traits. The hypotheses were that genome-wide DNA methylation levels in blood leukocytes are associated with plasma total carotenoid concentrations and that clusters of genes associated with carotenoids are also correlated to lipid profile traits. Our results highlighted the potential implication of gene co-methylation in the relationship between plasma carotenoids and lipid profile.

\section{Materials and Methods}

\subsection{Patients and Design}

The GENERATION Study aimed at evaluating familial resemblances in omics (DNA methylation [23] and gene expression [24]) and metabolic (metabolites [25] and carotenoids [8]) profiles in healthy families. The GENERATION Study comprises a total of 48 French-Canadian subjects from 16 families of Quebec City (Canada). Families composed of 16 mothers, six fathers, and 26 children lived under the same roof. Families comprised at least the mother and one child (8-18 years old). Parents had to be the biological parents of their child (or children), non-smokers, with body mass index (BMI) ranging between 18 and $35 \mathrm{~kg} / \mathrm{m}^{2}$, and free of any metabolic conditions requiring treatment (Synthroid ${ }^{\circledR}$ (levothyroxine) and oral contraceptive were tolerated). Children also had to be non-smokers, in good general health and not using psycho-stimulators (Ritalin ${ }^{\circledR}$ (methylphenidate), Concerta ${ }^{\circledR}$ (methylphenidate), and Strattera ${ }^{\circledR}$ (atomoxetine)). Blood samples were taken from both parents and children at the Institute of Nutrition and Functional Foods (INAF). The experimental protocol was approved by the Ethics Committees of Laval University Hospital Research Center and Laval University. All participants signed an informed consent document. Parental consent was also obtained by signing the child consent document.

\subsection{Anthropometric and CM Measurements}

Body weight and height were measured [26]. Blood samples were collected from an antecubital vein into vacutainer tubes containing EDTA after 12-hour fast and 48-hour alcohol abstinence. Plasma was separated by centrifugation $\left(2500 \mathrm{~g}\right.$ for $10 \mathrm{~min}$ at $\left.4{ }^{\circ} \mathrm{C}\right)$, and samples were aliquoted and frozen $\left(-80^{\circ} \mathrm{C}\right)$. Plasma TC and TG concentrations were measured using enzymatic assays $[27,28]$. Precipitation of 
very-low density lipoprotein and LDL particles in the infranatant with heparin manganese chloride generated the HDL-C fraction for measurements of HDL levels [29]. LDL-C was estimated using the Friedewald formula [30]. The rocket immunoelectrophoretic method was used to measure plasma apolipoprotein B-100 (ApoB100) concentrations [31]. Plasma C-reactive protein (CRP) was measured by nephelometry using a sensitive assay (Prospec equipment Behring) [32]. Fasting plasma glucose concentrations were enzymatically measured [33]. Radioimmunoassay with polyethylene glycol separation was used to measure fasting plasma insulin concentrations [34].

\subsection{DNA Extraction and Methylation Analysis}

Genomic DNA was extracted from blood leukocytes using the GenElute Blood Genomic DNA kit (Sigma-Aldrich, St. Louis, MO, USA) in all 48 subjects. NanoDrop Spectrophotometer (Thermo Scientific, Wilmington, DE, USA) and PicoGreen DNA methods were used to quantify DNA. Infinium Human Methylation 450 array (Illumina, San Diego, CA, USA) was used to measure DNA methylation levels. McGill University and Genome Quebec Innovation Center (Montreal, QC, Canada) proceeded to the bisulfite conversion and quantitative DNA methylation analysis. Methylation data on all 485,577 CpG sites were analyzed using Illumina GenomeStudio software v2011.1 and the Methylation Module. All samples were retained after quality control steps [23]. GenomeStudio was used to perform global normalization using control probes. Probes with a detection $p$-value $>0.01$ in more than 5 subjects ( $>10 \%$ of all subjects) were removed. We restricted our analysis to autosomes and multi-mapped probes were also excluded [35]. Thus, 472,245 probes were considered in the analysis.

\subsection{Carotenoid Measurements}

Samples and standards preparation has been reported previously [8]. Briefly, $100 \mu \mathrm{L}$ of fasting plasma samples were thawed a few hours before analysis and transferred to Eppendorf tubes with $20 \mu \mathrm{L}$ of 2-propanol, and $20 \mu \mathrm{L}$ of carotenoid standard. Samples were transferred on a $400 \mu \mathrm{L}$ fixed well plate (ISOLUTE ${ }^{\circledR}$ SLE+, Biotage, Charlotte, NC, USA) with $900 \mu \mathrm{L}$ of hexane:isopropanol (90/10, $v / v)$ in each well. Each extracted sample was evaporated under nitrogen and reconstituted with $300 \mu \mathrm{L}$ of methanol:dichloromethane $(65 / 35, v / v)$. Plates were shaken for $10 \mathrm{~min}$ and samples were transferred into high performance liquid chromatography glass vials.

Agilent 1260 liquid handling system (Agilent, Mississauga, ON, Canada) was used to perform high performance liquid chromatography (HPLC)-UV analysis as previously described [8]. Carotenoids were separated with a mobile phase consisting of methanol:water (98/2, v/v; Eluent A) and methyl-tert-butyl ether (MTBE; Eluent B; VWR, Mississauga, ON, Canada). Flow-rate and gradient elution are detailed in a previous paper [8]. UV detector was set at $450 \mathrm{~nm}$ and identification of each compound was confirmed using retention time and UV spectra (190-640nm) of the pure compounds. The Chemstation software (Agilent, Mississauga, ON, Canada) was used to carry out data acquisition. The carotenoid concentrations are reported in $\mu \mathrm{mol} / \mathrm{L}$ of plasma. One value for $\beta$-crypoxanthin was considered an outlier (defined as a value falling outside of the mean \pm 4 standard deviations) and was excluded from analyses. The exclusion of this outlier is likely to have very little impact on further analysis, considering that it affected only one subject, and the mean of total carotenoids remained very similar ( $6.00 \mu \mathrm{mol} / \mathrm{L}$ without the outlier and $6.04 \mu \mathrm{mol} / \mathrm{L}$ including the outlier).

\subsection{Association between DNA Methylation Levels and Total Carotenoid Concentrations}

Concentrations of plasma carotenoids are available in Supplementary Table S1. Plasma total carotenoid concentrations ( $\mu \mathrm{mol} / \mathrm{L}$ of plasma) were defined as the sum of $\alpha$-carotene, $\beta$-carotene, $\beta$-cryptoxanthin, lutein, lycopene, and zeaxanthin concentrations. Regressions between normalized DNA methylation levels of all 472,245 CpG sites and total carotenoid concentrations adjusted for the family ID were computed using R software v2.14.1 (R Foundation for Statistical Computing; http://www.r-project.org) [36]. Plasma total carotenoid concentrations (independent variable) were used to predict DNA methylation levels (dependent variable). A $p$-value $\leq 0.05$ was used to identify 
significant associations. Regressions were adjusted for family ID (fixed effect) to account for the familial structure. In order to maintain a more exploratory approach, the regressions were not adjusted for other confounding factors. Choices of linear model and confounding factors were made for comparison purposes with similar study by our group [37]. Weighted gene correlation network analysis (WGCNA) was performed with methylation levels of 20,687 CpG sites showing a significant association ( $p$-value $\leq 0.05$ ) with total carotenoid concentrations. This allowed evaluating co-methylation similarities only in $\mathrm{CPG}$ sites that are associated with carotenoids.

\subsection{Weighted Gene Correlation Network Analysis (WGCNA)}

WGCNA was performed with the WGCNA package [22,38] in R software using default parameters [36]. A weighted adjacency matrix was established by calculating Pearson correlations between each CpG site pair. The co-methylation similarity matrix was raised to a power $\beta=5\left(R^{2}\right.$ of 0.9570) to calculate weighted adjacency matrix [39] (Supplementary Figure S1). From this matrix, values were used to construct a topological overlap matrix (TOM), which provided a similarity measure. The TOM is then used to calculate the corresponding dissimilarity (1-TOM). Next, CpG sites with coherent methylation profiles were grouped into modules using the average linkage hierarchical clustering applied to the TOM-based dissimilarity [39]. The dynamic tree cutting algorithm (function = cutreeDynamic, deep split $=0$, minimum number of genes per module $=40$, cut height $=0.25$ ) was used to detect methylation modules (clusters of densely interconnected $\mathrm{CpG}$ sites in terms of co-methylation). The assignment of outlying genes to modules was performed using the Partitioning Around Medoids (PAM) method. DNA methylation levels of CpG sites within a module were summarized with the module eigengene (ME) value, which is the overall methylation level of $\mathrm{CpG}$ sites clustering in a module. To identify modules that were significantly associated with lipid profile traits (TC, LDL-C, HDL-C, TG, ApoB100), correlation between MEs [40] and traits were computed. Associations of individual genes with lipid profile traits was quantified using gene significance (GS), defined as the absolute correlation between the gene and the trait. Module membership (MM), defined as the correlation of the ME and the gene methylation profile, was used to quantify the similarity of all genes to each module. Correlations between MM and GS were computed to identify modules of interest. We considered CPG sites with the highest MM and GS to be those of highest biological relevance [41]. CpG sites with a GS $>0.2$, a MM $>0.8$, and a $p$-value $\leq 0.05$ were retained as hub genes. Due to the high number of hub genes obtained $(n=2734)$, genes were subsequently ordered according to their GS with the trait. A total of three top annotated hub genes were selected in each of the six module-lipid associations, for a total of 18 top hub genes. VisANT 5.0 was used to construct and visualize the topological interaction network in the black, turquoise, and pink modules [42]. VisANT is a software framework for mining, analyzing and visualizing hierarchical organization of biological networks [43]. Weighted correlation cut-offs of $0.23,0.44$, and 0.27 were used for the black, turquoise, and pink modules, respectively. The cut-offs were chosen to obtain visually interpretable networks, without being too heavily loaded. Central genes were those with the most gene-gene connections. Enrichr (http://amp.pharm.mssm.edu/Enrichr/) was used to obtain KEGG pathways 2019 and Gene Ontology molecular functions 2018 associated with genes in the black, turquoise, and pink modules [44].

\section{Results}

\subsection{Characteristics and Biochemical Parameters}

Characteristics and biochemical parameters including plasma total carotenoid concentrations of the parents and children are presented in Table 1. Plasma concentrations of the six main carotenoids ( $\alpha$-carotene, $\beta$-carotene, $\beta$-cryptoxanthin, lutein, lycopene, and zeaxanthin) and of total carotenoids concentrations measured in each participant are presented in Supplementary Table S1. 
Table 1. Characteristic and biochemical parameters.

\begin{tabular}{ccc}
\hline Biochemical Parameters & Parents $(\boldsymbol{n = 2 2 )}$ & Children $(\boldsymbol{n}=\mathbf{2 6})$ \\
\hline Age $($ years $)$ & $42.3 \pm 5.3$ & $11.3 \pm 3.4$ \\
BMI $\left(\mathrm{kg} / \mathrm{m}^{2}\right)$ & $23.9 \pm 3.0$ & - \\
BMI percentile & - & $50 \pm 31.1$ \\
TC $(\mathrm{mmol} / \mathrm{L})$ & $4.68 \pm 0.55$ & $4.28 \pm 0.51$ \\
HDL-C $(\mathrm{mmol} / \mathrm{L})$ & $1.63 \pm 0.38$ & $1.55 \pm 0.29$ \\
LDL-C $(\mathrm{mmol} / \mathrm{L})$ & $2.61 \pm 0.55$ & $2.31 \pm 0.45$ \\
TC/HDL-C & $3.02 \pm 0.78$ & $2.83 \pm 0.47$ \\
ApoB100 $(\mathrm{g} / \mathrm{L})$ & $0.80 \pm 0.15$ & $0.70 \pm 0.13$ \\
TG $(\mathrm{mmol} / \mathrm{L})$ & $0.95 \pm 0.35$ & $0.93 \pm 0.39$ \\
Glucose $(\mathrm{mmol} / \mathrm{L})$ & $5.20 \pm 0.34$ & $4.86 \pm 0.23$ \\
Insulin $(\mathrm{pmol} / \mathrm{L})$ & $66.59 \pm 33.54$ & $73.00 \pm 28.96$ \\
CRP $(\mathrm{mg} / \mathrm{L})$ & $0.77 \pm 0.84$ & $0.43 \pm 0.66$ \\
Total carotenoids $(\mu \mathrm{mol} / \mathrm{L})$ & $6.35 \pm 2.39$ & $5.70 \pm 2.05$
\end{tabular}

All values are means \pm SD. Abbreviations: Apolipoprotein B100 (ApoB100), body mass index (BMI), C-reactive protein (CRP), high-density lipoprotein cholesterol (HDL-C), low-density lipoprotein cholesterol (LDL-C), standard deviation (SD), total cholesterol (TC), total cholesterol/HDL-C (TC/HDL-C), triglycerides (TG).

\subsection{Weighted Gene Correlation Network Analysis (WGCNA)}

Normalized methylation levels of all 472,245 CpG sites were tested for associations with plasma total carotenoid concentrations using regressions. A total of 20,687 CpG sites were significantly associated ( $p \leq 0.05)$ with total carotenoids (Supplementary Table S2). This subset of CpG sites associated with total carotenoids was then related to lipid profile traits using WGCNA.

A total of nine distinct modules were identified from methylation levels of the 20,687 CpG sites associated with total carotenoid concentrations using a dynamic tree cutting algorithm (Figure 1). Using a cut-off height of 0.25 for the clustering of module eigengenes (MEs) (merged dynamic), none of the modules has merged (Figure 1). The black, blue, brown, green, grey, pink, red, turquoise, and yellow modules contained 431, 3308, 3235, 2096, 1479, 243, 482, 7119, and 2294 CpG sites, respectively. The 1479 uncorrelated $\mathrm{CpG}$ sites were assigned to the grey module, which was excluded from further analysis. Correlations between MEs and lipid profile traits (TC, LDL-C, HDL-C, TG, ApoB100) were computed to find modules of interest. According to the heatmap of module-trait correlations (Figure 2), ME of the black module (431 CpG sites) had a negative correlation with HDL-C $(r=-0.34 p=0.017)$. The ME of the turquoise module (7119 CpG sites) had negative correlations with TC $(r=-0.46 p=0.0011)$, HDL-C $(r=-0.30 p=0.036)$, LDL-C $(r=-0.32 p=0.028)$, and ApoB100 $(r=-0.34 p=0.018)$. The ME of the pink module (243 CpG sites) had a negative correlation with HDL-C $(r=-0.29 p=0.048)$.

Gene significance (GS) (i.e., correlation between CpG site methylation and lipid profile traits) was correlated to module membership (MM) (i.e., correlation of the ME and the CpG site methylation profile). In the black module, GS for HDL-C had a significant correlation with the MM $(r=0.25$ $p=1.5 \times 10^{-7}$ ) (Supplementary Figure S2). In the turquoise module, GS for TC, HDL-C, LDL-C, and ApoB100 had significant correlations with the MM $\left(r=0.46 p<1 \times 10^{-200}, r=0.17 p=2.6 \times 10^{-47}\right.$, $r=0.41 p<1 \times 10^{-200}$, and $r=0.43 p<1 \times 10^{-200}$, respectively) (Supplementary Figure S2). In the pink module, GS for HDL-C had a significant correlation with the MM $\left(r=0.37 p=2.7 \times 10^{-9}\right)$ (Supplementary Figure S2). Hence, the black, turquoise, and pink modules were considered as modules of interest for subsequent analyses. 
Cluster Dendrogram

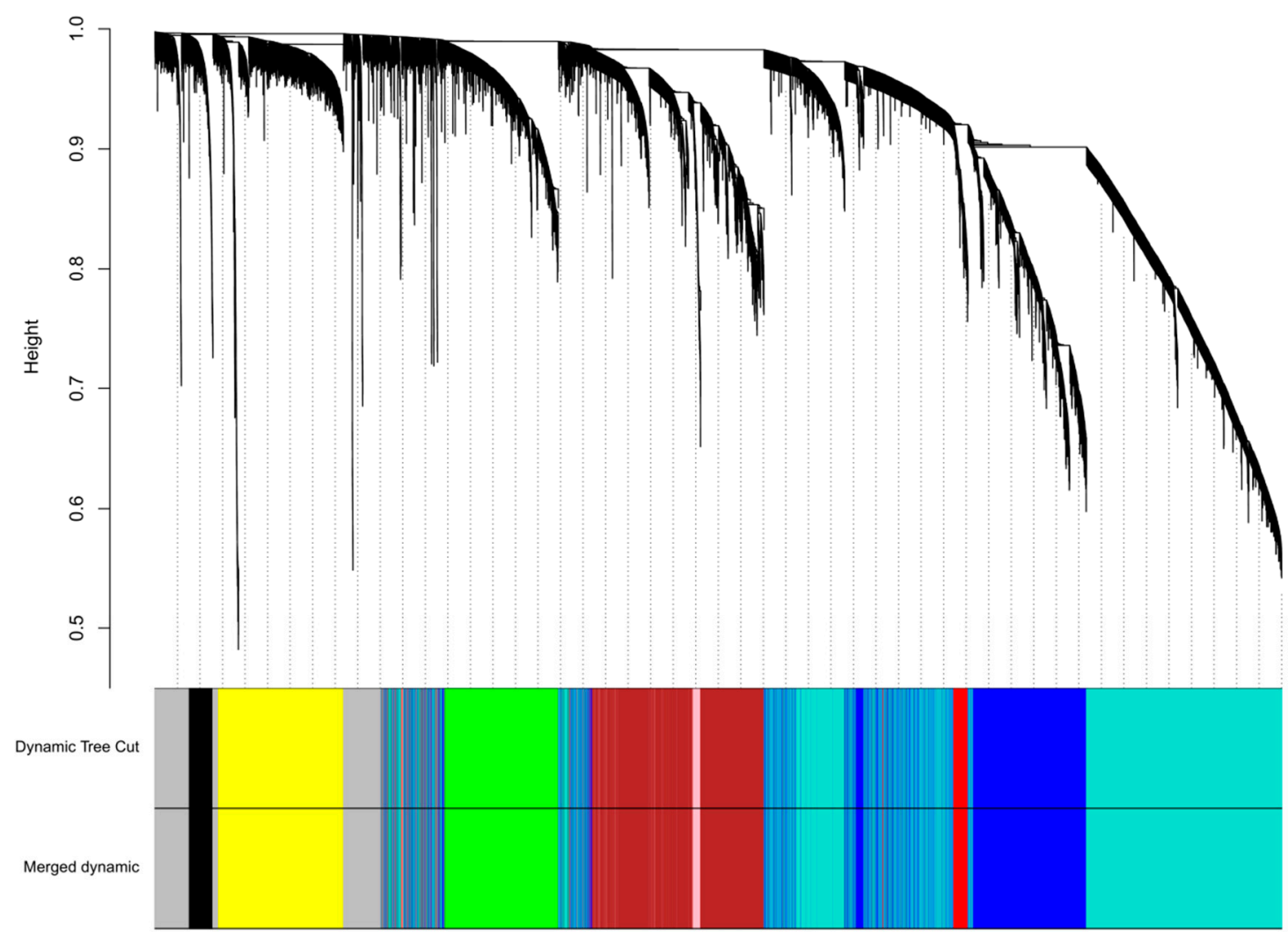

Figure 1. Gene dendogram obtained using average linkage hierarchical clustering. The dynamic tree cut yielded nine modules. The merged dynamic yielded same modules as the dynamic tree cut using a cut-off of 0.25 . Module colors are shown correspondingly.

Module-trait relationships

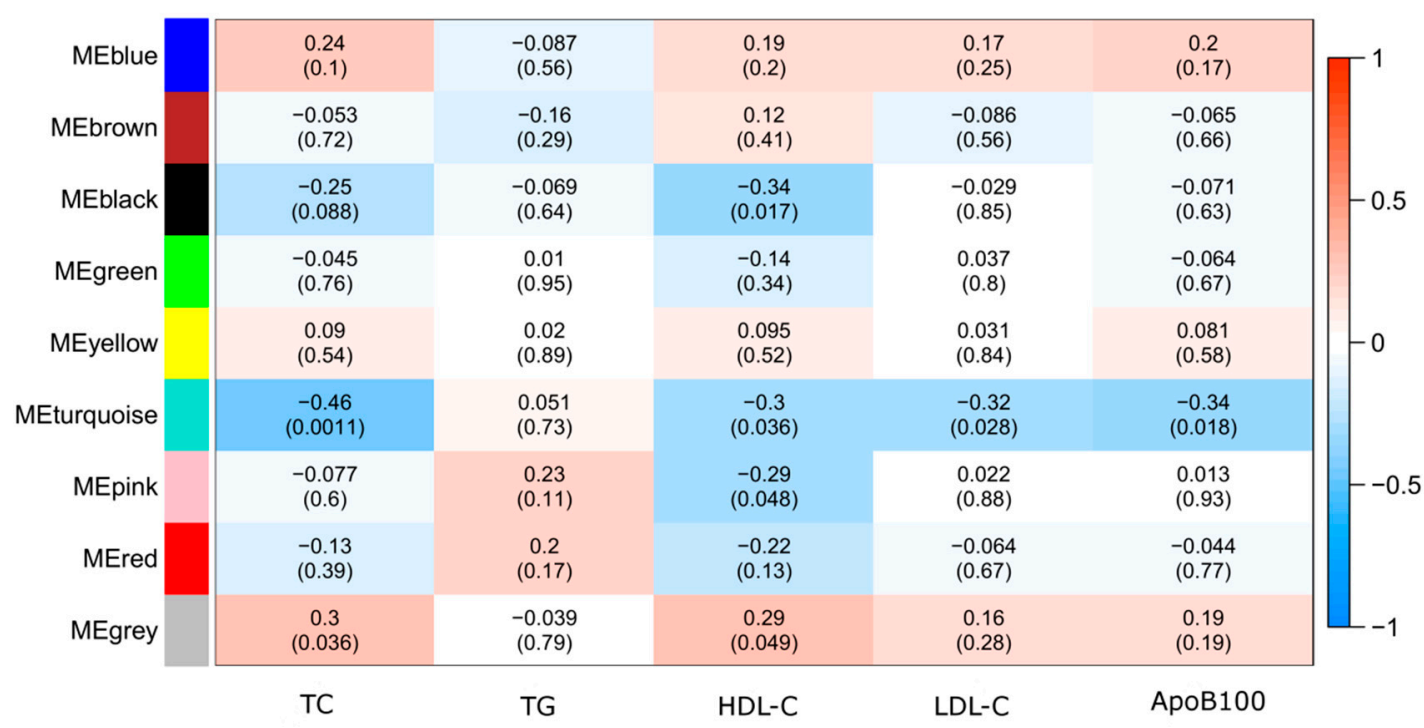

Figure 2. Heatmap of module-trait relationships depicting correlations between module eigengenes and lipid profile traits. Numbers in the table correspond to the correlation $r$ and the $p$-value in parentheses. The degree of correlation is illustrated with the color legend. Abbreviations: Apolipoprotein B100 (ApoB100), high-density lipoprotein cholesterol (HDL-C), low-density lipoprotein cholesterol (LDL-C), module eigengene (ME), total cholesterol (TC), triglycerides (TG). 


\subsection{Hub Gene Analysis}

Hub gene analysis in black, turquoise, and pink modules was conducted to explore the underlying mechanisms behind the associations observed. A total of 17, 2700, and 17 hub genes were identified in the black, turquoise, and pink modules, respectively (Supplementary Table S3). Due to their high number, hub genes were subsequently ordered according to their GS with the trait. Top three most significant hub genes were selected in each module-lipid association, for a total of 18 top hub genes (Table 2). In the black module, PAX4, TBC1D16, and PGA5 were the top three hub genes associated with HDL-C. In the turquoise module, RBL2, GRIN3A, and TEX2 were the top three hub genes associated with TC, while LST1, GOSR1, and GBGT1 were associated with HDL-C, C7orf50, PDPK1, SYT17 with LDL-C, and finally GABBR1, RAG2, and C7orf50 were associated with ApoB100 (Table 2). In the pink module, RNASE11, TRIM68, and DEPDC1 were the top three hub genes associated with HDL-C (Table 2).

Table 2. Top hub genes identified from WGCNA analysis.

\begin{tabular}{|c|c|c|c|c|c|c|}
\hline Module-Lipid & CpG Site & $\begin{array}{c}\text { Gene } \\
\text { (Chr, Accession Number) }\end{array}$ & GS & $\begin{array}{c}p \text {-Value } \\
\text { GS }\end{array}$ & MM & $\begin{array}{c}p \text {-Value } \\
\text { MM }\end{array}$ \\
\hline \multirow{3}{*}{$\begin{array}{l}\text { Black } \\
\text { HDL-C }\end{array}$} & cg01999908 & $\begin{array}{c}\text { PAX4 } \\
\text { (Chr7, NM_006193) }\end{array}$ & -0.37 & 0.0092 & 0.85 & $2.10 \times 10^{-14}$ \\
\hline & cg08731068 & $\begin{array}{c}\text { TBC1D16 } \\
\text { (Chr17, NM_019020) }\end{array}$ & -0.37 & 0.011 & 0.89 & $1.70 \times 10^{-17}$ \\
\hline & cg04010296 & $\begin{array}{c}\text { PGA5 } \\
\text { (Chr11, NM_014224) }\end{array}$ & -0.36 & 0.011 & 0.83 & $4.08 \times 10^{-13}$ \\
\hline \multirow{3}{*}{$\begin{array}{l}\text { Turquoise } \\
\text { TC }\end{array}$} & cg00000029 & $\begin{array}{c}\text { RBL2 } \\
\text { (Chr16, NM_005611) }\end{array}$ & -0.59 & $8.49 \times 10^{-6}$ & 0.83 & $3.45 \times 10^{-13}$ \\
\hline & cg02500883 & $\begin{array}{c}\text { GRIN3A } \\
\text { (Chr9, NM_133445) }\end{array}$ & -0.57 & $1.98 \times 10^{-5}$ & 0.81 & $2.52 \times 10^{-12}$ \\
\hline & cg00864012 & $\begin{array}{c}\text { TEX2 } \\
\text { (Chr17, NM_018469) }\end{array}$ & -0.56 & $3.39 \times 10^{-5}$ & 0.85 & $2.39 \times 10^{-14}$ \\
\hline \multirow{3}{*}{$\begin{array}{l}\text { Turquoise } \\
\text { HDL-C }\end{array}$} & cg27616007 & $\begin{array}{c}\text { LST1 } \\
(\text { Chr6, NR_029461) }\end{array}$ & -0.42 & 0.0027 & 0.81 & $3.82 \times 10^{-12}$ \\
\hline & cg24240870 & $\begin{array}{c}\text { GOSR1 } \\
\text { (Chr17, NM_004871) }\end{array}$ & -0.42 & 0.0030 & 0.81 & $4.55 \times 10^{-12}$ \\
\hline & cg18089000 & $\begin{array}{c}\text { GBGT1 } \\
\text { (Chr9, NM_021996) }\end{array}$ & -0.42 & 0.0031 & 0.86 & $3.88 \times 10^{-15}$ \\
\hline \multirow{3}{*}{$\begin{array}{l}\text { Turquoise } \\
\text { LDL-C }\end{array}$} & cg07665923 & $\begin{array}{c}\text { C7orf50 } \\
\text { (Chr7, NM_001134396) }\end{array}$ & -0.45 & 0.0012 & 0.83 & $2.22 \times 10^{-13}$ \\
\hline & cg02119755 & $\begin{array}{c}\text { PDPK1 } \\
\text { (Chr16, NM_031268) }\end{array}$ & -0.44 & 0.0017 & 0.87 & $1.62 \times 10^{-15}$ \\
\hline & cg06142108 & $\begin{array}{c}\text { SYT17 } \\
\text { (Chr16, NM_016524) }\end{array}$ & -0.43 & 0.0022 & 0.88 & $1.75 \times 10^{-16}$ \\
\hline \multirow{3}{*}{$\begin{array}{l}\text { Turquoise } \\
\text { ApoB100 }\end{array}$} & $\operatorname{cg} 17053201$ & $\begin{array}{c}\text { GABBR1 } \\
(\text { Chr6, NM_021904) }\end{array}$ & -0.46 & 0.00096 & 0.82 & $8.40 \times 10^{-13}$ \\
\hline & cg21671607 & $\begin{array}{c}\text { RAG2 } \\
\text { (Chr11, NM_000536) }\end{array}$ & -0.46 & 0.0011 & 0.84 & $7.35 \times 10^{-14}$ \\
\hline & cg07665923 & $\begin{array}{c}\text { C7orf50 } \\
\text { (Chr7, NM_001134396) }\end{array}$ & -0.46 & 0.0011 & 0.83 & $2.22 \times 10^{-13}$ \\
\hline \multirow{3}{*}{$\begin{array}{c}\text { Pink } \\
\text { HDL-C }\end{array}$} & cg15505294 & $\begin{array}{c}\text { RNASE11 } \\
\text { (Chr14, NM_145250) }\end{array}$ & 0.36 & 0.012 & -0.95 & $1.87 \times 10^{-24}$ \\
\hline & cg01719157 & $\begin{array}{c}\text { TRIM68 } \\
\text { (Chr11, NM_018073) }\end{array}$ & -0.35 & 0.013 & 0.81 & $4.10 \times 10^{-12}$ \\
\hline & cg09113768 & $\begin{array}{c}\text { DEPDC1 } \\
\text { (Chr1, NM_017779) }\end{array}$ & -0.35 & 0.015 & 0.83 & $2.22 \times 10^{-13}$ \\
\hline
\end{tabular}

Abbreviations: Apolipoprotein B100 (ApoB100), chromosome (Chr), cytosine-phosphate-guanine (CpG), gene significance (GS), high-density lipoprotein cholesterol (HDL-C), low-density lipoprotein cholesterol (LDL-C), module membership (MM), total cholesterol (TC) weighted gene correlation network analysis (WGCNA). 


\subsection{Topological Interaction Networks}

Topological interaction networks were used to illustrate gene-gene interactions within the black, turquoise, and pink modules. In order not to overload networks, weighted correlation cut-offs were used. In the black module containing $431 \mathrm{CpG}$ sites, only annotated CpG sites with a weighted correlation of 0.23 were included ( $n=14$ unique genes) (Figure 3 ). In the turquoise module containing 7119 CpG sites, only annotated CpG sites with a weighted correlation of 0.44 were included $(n=20$ unique genes) (Figure 4). In the pink module containing 243 CpG sites, only annotated CpG sites with a weighted correlation of 0.27 were included ( $n=13$ unique genes) (Figure 5). Gene Ontology molecular functions and KEGG pathways of genes in the black, turquoise and pink modules are presented in Supplementary Table S4.

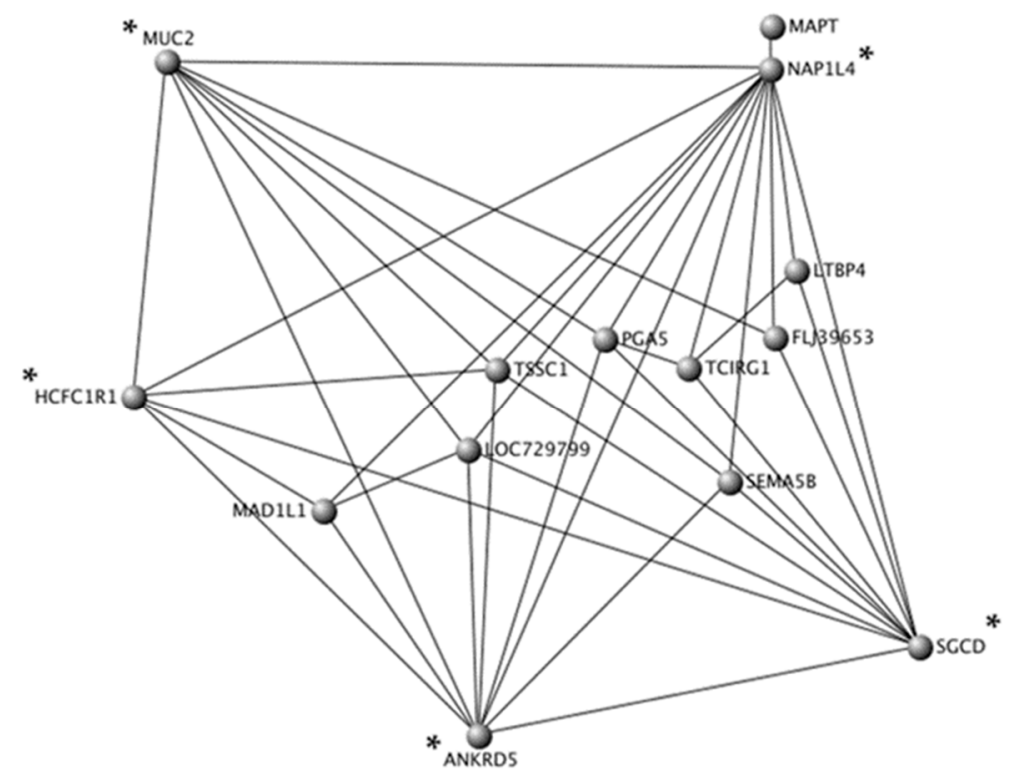

Figure 3. Topological interaction network of 14 unique genes in the black module. Each gene is represented by a node and edge number is proportional to connection strength. Gene-gene interaction network was constructed and visualized using VisANT 5.0. Central genes are identified using asterisks.

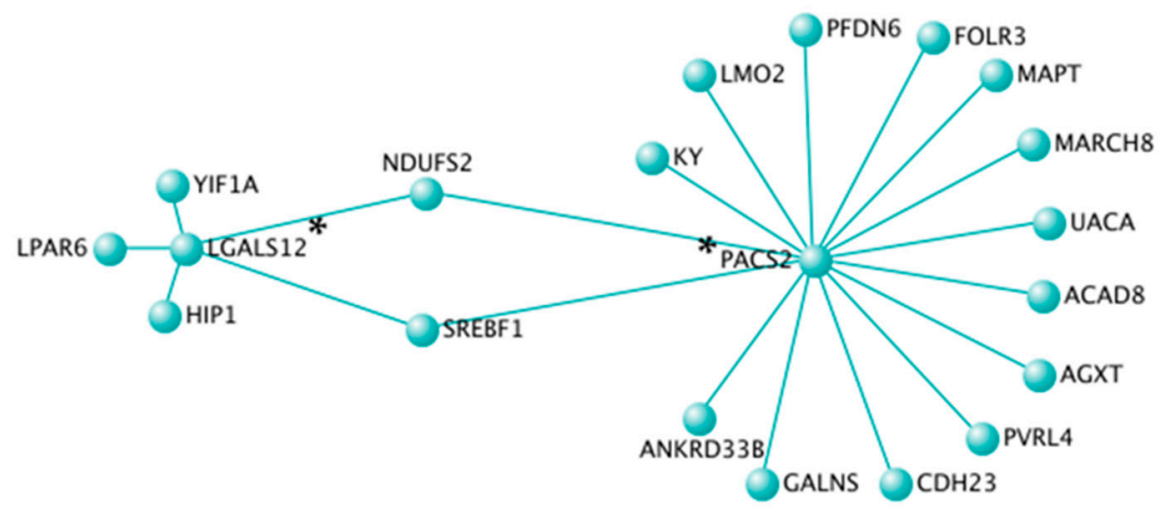

Figure 4. Topological interaction network of 20 unique genes in the turquoise module. Each gene is represented by a node and edge number is proportional to connection strength. Gene-gene interaction network was constructed and visualized using VisANT 5.0. Central genes are identified using asterisks. 


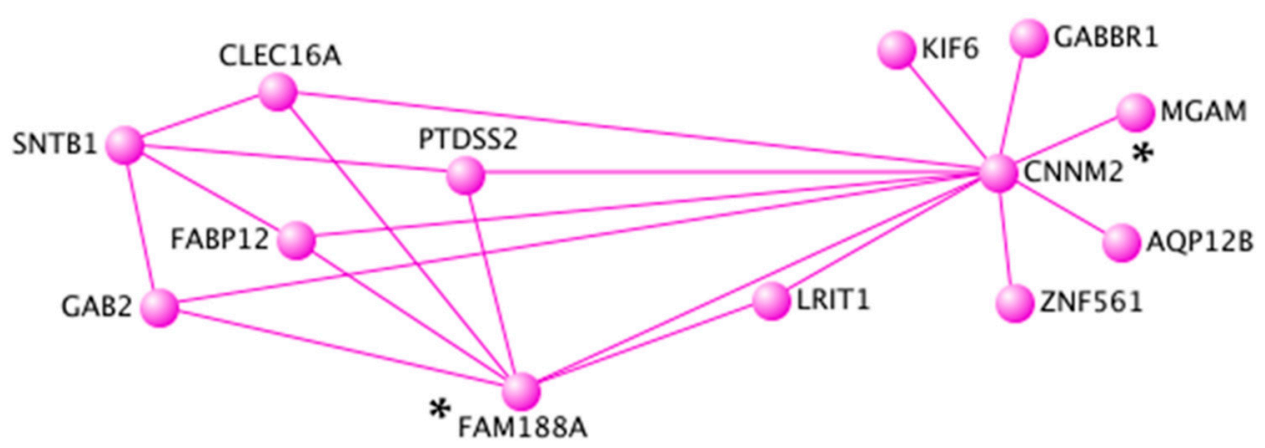

Figure 5. Topological interaction network of 13 unique genes in the pink module. Each gene is represented by a node and edge number is proportional to connection strength. Gene-gene interaction network was constructed and visualized using VisANT 5.0. Central genes are identified using asterisks.

\section{Discussion}

First, in order to identify $\mathrm{CpG}$ sites associated with carotenoids, associations between genome-wide DNA methylation levels and plasma total carotenoid concentrations were tested. A total of 20,687 CpG sites were significantly associated with total carotenoid concentrations. To the best of our knowledge, this is the first study that considered the association of plasma total carotenoid concentrations with genome-wide DNA methylation levels. Until now, studies have been mainly focusing on the effect of genetic variants (SNPs) on the variability in carotenoid concentrations [45-47]. Circulating carotenoids have also been shown to have an impact on gene expression via transcription factors [16]. However, very few studies have considered the impact of carotenoids on DNA methylation. In two cell studies, lycopene had modest to null effects on DNA methylation of GSTP1, which is involved in prostate and breast cancers [17,18]. In addition, a study of 165 overweight and obese subjects observed positive associations between $H E R V$-w methylation and dietary intakes of $\beta$-carotene and carotenoids, while TNF $\alpha$ methylation showed negative associations with dietary intakes of $\beta$-carotene and carotenoids [19]. Moreover, blood carotenoid levels were also associated with extrinsic epigenetic age acceleration [20]. Thus, the relationship between carotenoids and DNA methylation has not been widely studied using pan-genomic tools. A potential mechanism underlying the action of carotenoids on DNA methylation is the inhibition of the DNA methyltransferase (DNMT). Studies have shown that carotenoids (lycopene and astaxanthin) decreased DNMT activity and protein level in vitro $[48,49]$.

Secondly, modules and key hub genes related to lipid profile traits in the subset of 20,687 CpG sites associated with carotenoid concentrations were identified using WGCNA. Among nine modules identified, MEs of the black and pink modules had a significant correlation with HDL-C, while ME of the turquoise module had significant correlations with TC, HDL-C, LDL-C, and ApoB100. Thus, highly co-methylated genes in the black, turquoise, and pink modules may have potential interactions or biological effects on lipid concentrations. Moreover, these modules also showed positive correlations between GS for several lipid profile traits and the MM of the respective module. This suggests that genes showing a strong association with lipid profile traits were also the most important elements of their respective module. The analysis with hub genes allowed getting insights on the potential mechanisms linking carotenoid concentrations and lipid profile. Three top hub genes were selected in each of the six module-lipid associations. Among these 18 top hub genes (17 unique top hub genes), several were related to lipid profile. First, cg07665923 is located in C7orf50. Several SNPs within this gene have been associated with TC. Indeed, SNP rs1997243 was associated with TC in a genome-wide association study on 188,577 individuals [50]. Moreover, another SNP (rs6951245) has been shown to be a novel pleiotropic locus for both CRP and TC [51]. SNP rs11763835 is also a peak cis-microRNA-eQTL associated with TC [52]. Second, cg02500883 is located in GRIN3A, encoding for a glutamate ionotropic receptor NMDA type subunit 3A. SNPs within this gene have been associated with circulating lipid concentrations $[53,54]$. Interestingly, treatment with astaxanthin, a xanthophyll carotenoid, in rat neurons reduced GRIN3A gene expression [55]. Third, cg21671607 is located in RAG2, encoding for the 
recombination activating 2. Variations in this gene are associated with several clinical phenotypes going from severe, early-onset infections to inflammation and autoimmunity [56]. Interestingly ApoE and $R A G 2-d e f i c e n t$ mice have lower plasma TC levels than do immune-competent apoE mice suggesting an effect of the immune system on plasma lipid homeostasis [57]. Finally, cg24240870 is located in GOSR1 (GS28), encoding for the Golgi SNAP receptor complex member 1, which transports proteins among the endoplasmic reticulum and the Golgi, and between Golgi compartments. In murine melanocytes, 25-hydroxycholesterol reduced protein levels of GS28 and may be linked to cholesterol homeostasis through an OSBP-related protein [58].

Moreover, topological interaction network visualization represented another method to identify novel central genes in co-methylation modules. In the black module, five central genes were identified (ANKRD5, HCFC1R1, MUC2, NAP1L4, and SGCD). A genetic variant (rs7935422) in NAP1L4, encoding for a nucleosome assembly protein 1 like 4 , has been associated with HDL-C concentrations in various populations [59]. Moreover, genetic variants in $S G C D$, encoding for a sarcoglycan delta, have been associated with circulating lipid concentrations [54] and HDL particle size [60]. In the turquoise module, two central genes were identified (PACS2 and LGALS12). Interestingly, PACS2 impacts lipid metabolism by controlling formation of endoplasmic reticulum lipid-synthesizing centers, which are found on mitochondria-associated membranes [61]. Moreover, LGALS12 is encoding for the galectin 12. Expression of LGALS12 in adipocytes is up-regulated by PPAR- $\gamma$ agonists suggesting its role in insulin signaling and type-2 diabetes [62]. In the pink module, two central genes were identified (CNNM2 and FAM188A). A genetic variant in CNNM2, encoding for a cyclin and CBS domain divalent metal cation transport mediator 2, has been associated with coronary artery disease and blood pressure [63-65]. In summary, several hub genes and central genes were related to lipid metabolism, immune and inflammatory response, and the sensible connection between the two.

The present study has some limitations. The main limitation lies in the small sample size, which may reduce variability in DNA methylation levels, as well as limiting the statistical power to detect CpG sites associated with total carotenoid concentrations. We did not account for multiple testing, since we used an exploratory approach and did not want this study to be overly constrained. However, WGCNA allowed reducing the impact of multiple testing by grouping the 20,687 CpG sites into nine modules. Despite the fact that DNA methylation in blood leukocytes is representative of DNA methylation in other tissues [66], it is influenced by cell composition. However, the impact of cell composition was not taken into account in the present analyses. In a previous paper by our group, cell heterogeneity was predicted using DNA methylation levels, and it estimated proportions of six different cell types [24]. These six additional cofounders were not included in the present analysis in order to prevent the reduction of the statistical power to detect significant associations and correlations. Finally, our study did not account for diet, physical activity, smoking, and alcohol consumption of the participants, all of which may affect circulating carotenoid concentrations $[67,68]$.

\section{Conclusions}

In conclusion, DNA methylation levels of 20,687 CpG sites were associated with plasma total carotenoid concentrations. Using WGCNA, nine co-methylation modules were identified. A total of 2734 hub genes, and more specifically 17 unique top hub genes, associated with total carotenoid concentrations were potentially related to lipid profile traits. Even though further studies and validation of the hub genes are needed, this research provides evidence for the potential role of gene co-methylation in the relationship between carotenoids, lipid profile and ultimately $\mathrm{CM}$ health.

Supplementary Materials: The following are available online at http://www.mdpi.com/2072-6643/11/6/1265/s1, Figure S1: Scale independence and mean connectivity; Figure S2: Scatterplots of gene significance for lipid profile traits and module membership in the A) black-HDL-C B) pink-HDL-C C) turquoise-TC D) turquoise-HDL-C E) turquoise-LDL-C and F) turquoise-ApoB100; Table S1: Concentrations of plasma carotenoids ( $\mu \mathrm{mol} / \mathrm{L}$ of plasma); Table S2: CpG sites showing significant correlation with plasma total carotenoids $(n=20,687)$; Table S3: Hub genes identified from WGCNA analysis $(n=2734)$; Table S4: Molecular functions and pathways in the black, turquoise and pink modules. 
Author Contributions: Conceptualization, B.L. and M.-C.V.; Data curation, B.L.T., F.G. and L.P.; Formal analysis, B.L.T. and F.G.; Funding acquisition, M.-C.V.; Investigation, B.L. and M.-C.V.; Methodology, B.L.T., F.G. and M.-C.V.; Project administration, M.-C.V.; Resources, L.P. and M.-C.V.; Software, B.L.T., and F.G.; Supervision, M.-C.V.; Visualization, B.L.T.; Writing - original draft, B.L.T.; Writing - review \& editing, B.L.T., F.G., B.L., L.P. and M.-C.V.

Funding: This work was supported by the Canada Research Chair in Genomics Applied to Nutrition and Metabolic Health.

Acknowledgments: We would like to thank Christian Couture, Véronique Garneau, and Catherine Raymond who contributed to the success of this study. This work was supported by the Canada Research Chair in Genomics Applied to Nutrition and Metabolic Health. MCV is Tier 1 Canada Research Chair in Genomics Applied to Nutrition and Metabolic Health. BLT is a recipient of a scholarship from the Canadian Institutes of Health Research (CIHR).

Conflicts of Interest: The authors declare no conflict of interest.

\section{References}

1. Guo, F.; Moellering, D.R.; Garvey, W.T. The progression of cardiometabolic disease: Validation of a new cardiometabolic disease staging system applicable to obesity. Obesity 2014, 22, 110-118. [CrossRef] [PubMed]

2. Martinez-Gonzalez, M.A.; de la Fuente-Arrillaga, C.; Lopez-Del-Burgo, C.; Vazquez-Ruiz, Z.; Benito, S.; Ruiz-Canela, M. Low consumption of fruit and vegetables and risk of chronic disease: A review of the epidemiological evidence and temporal trends among spanish graduates. Public Health Nutr. 2011, 14, 2309-2315. [CrossRef] [PubMed]

3. Couillard, C.; Lemieux, S.; Vohl, M.C.; Couture, P.; Lamarche, B. Carotenoids as biomarkers of fruit and vegetable intake in men and women. Br. J. Nutr. 2016, 116, 1206-1215. [CrossRef] [PubMed]

4. Maiani, G.; Caston, M.J.; Catasta, G.; Toti, E.; Cambrodon, I.G.; Bysted, A.; Granado-Lorencio, F.; Olmedilla-Alonso, B.; Knuthsen, P.; Valoti, M.; et al. Carotenoids: Actual knowledge on food sources, intakes, stability and bioavailability and their protective role in humans. Mol. Nutr. Food Res. 2009, 53 (Suppl. 2), S194-S218. [CrossRef]

5. Eroglu, A.; Harrison, E.H. Carotenoid metabolism in mammals, including man: Formation, occurrence, and function of apocarotenoids. J. Lipid Res. 2013, 54, 1719-1730. [CrossRef]

6. Allore, T.; Lemieux, S.; Vohl, M.C.; Couture, P.; Lamarche, B.; Couillard, C. Correlates of the difference in plasma carotenoid concentrations between men and women. Br. J. Nutr. 2019, 121, 172-181. [CrossRef]

7. Farook, V.S.; Reddivari, L.; Mummidi, S.; Puppala, S.; Arya, R.; Lopez-Alvarenga, J.C.; Fowler, S.P.; Chittoor, G.; Resendez, R.G.; Kumar, B.M.; et al. Genetics of serum carotenoid concentrations and their correlation with obesity-related traits in mexican american children. Am. J. Clin. Nutr. 2017, 106, 52-58. [CrossRef]

8. Tremblay, B.L.; Guenard, F.; Lamarche, B.; Perusse, L.; Vohl, M.C. Genetic and common environmental contributions to familial resemblances in plasma carotenoid concentrations in healthy families. Nutrients 2018, 10, 1002. [CrossRef]

9. Clevidence, B.A.; Bieri, J.G. Association of carotenoids with human plasma lipoproteins. Methods Enzymol. 1993, 214, 33-46.

10. D’Adamo, C.R.; D’Urso, A.; Ryan, K.A.; Yerges-Armstrong, L.M.; Semba, R.D.; Steinle, N.I.; Mitchell, B.D.; Shuldiner, A.R.; McArdle, P.F. A common variant in the setd7 gene predicts serum lycopene concentrations. Nutrients 2016, 8, 82. [CrossRef]

11. Beydoun, M.A.; Nalls, M.A.; Canas, J.A.; Evans, M.K.; Zonderman, A.B. Gene polymorphisms and gene scores linked to low serum carotenoid status and their associations with metabolic disturbance and depressive symptoms in african-american adults. Br. J. Nutr. 2014, 112, 992-1003. [CrossRef] [PubMed]

12. Ferrucci, L.; Perry, J.R.; Matteini, A.; Perola, M.; Tanaka, T.; Silander, K.; Rice, N.; Melzer, D.; Murray, A.; Cluett, C.; et al. Common variation in the beta-carotene 15,15'-monooxygenase 1 gene affects circulating levels of carotenoids: A genome-wide association study. Am. J. Hum. Genet. 2009, 84, 123-133. [CrossRef] [PubMed]

13. Zubair, N.; Kooperberg, C.; Liu, J.; Di, C.; Peters, U.; Neuhouser, M.L. Genetic variation predicts serum lycopene concentrations in a multiethnic population of postmenopausal women. J. Nutr. 2015, 145, 187-192. [CrossRef] [PubMed] 
14. Borel, P.; de Edelenyi, F.S.; Vincent-Baudry, S.; Malezet-Desmoulin, C.; Margotat, A.; Lyan, B.; Gorrand, J.M.; Meunier, N.; Drouault-Holowacz, S.; Bieuvelet, S. Genetic variants in bcmo1 and cd36 are associated with plasma lutein concentrations and macular pigment optical density in humans. Ann. Med. 2011, 43, 47-59. [CrossRef] [PubMed]

15. Bohn, T.; Desmarchelier, C.; Dragsted, L.O.; Nielsen, C.S.; Stahl, W.; Ruhl, R.; Keijer, J.; Borel, P. Host-related factors explaining interindividual variability of carotenoid bioavailability and tissue concentrations in humans. Mol. Nutr. Food Res. 2017, 61, 1600685. [CrossRef] [PubMed]

16. Sharoni, Y.; Danilenko, M.; Dubi, N.; Ben-Dor, A.; Levy, J. Carotenoids and transcription. Arch. Biochem. Biophys. 2004, 430, 89-96. [CrossRef] [PubMed]

17. Liu, A.G.; Erdman, J.W., Jr. Lycopene and apo-10'-lycopenal do not alter DNA methylation of gstp1 in lncap cells. Biochem. Biophys. Res. Commun. 2011, 412, 479-482. [CrossRef] [PubMed]

18. King-Batoon, A.; Leszczynska, J.M.; Klein, C.B. Modulation of gene methylation by genistein or lycopene in breast cancer cells. Environ. Mol. Mutagenes. 2008, 49, 36-45. [CrossRef]

19. Bollati, V.; Favero, C.; Albetti, B.; Tarantini, L.; Moroni, A.; Byun, H.M.; Motta, V.; Conti, D.M.; Tirelli, A.S.; Vigna, L.; et al. Nutrients intake is associated with DNA methylation of candidate inflammatory genes in a population of obese subjects. Nutrients 2014, 6, 4625-4639. [CrossRef]

20. Quach, A.; Levine, M.E.; Tanaka, T.; Lu, A.T.; Chen, B.H.; Ferrucci, L.; Ritz, B.; Bandinelli, S.; Neuhouser, M.L.; Beasley, J.M.; et al. Epigenetic clock analysis of diet, exercise, education, and lifestyle factors. Aging 2017, 9, 419-446. [CrossRef]

21. Mittelstrass, K.; Waldenberger, M. DNA methylation in human lipid metabolism and related diseases. Curr. Opin. Lipidol. 2018, 29, 116-124. [CrossRef] [PubMed]

22. Langfelder, P.; Horvath, S. Wgcna: An R package for weighted correlation network analysis. BMC Bioinform. 2008, 9, 559. [CrossRef] [PubMed]

23. Tremblay, B.L.; Guenard, F.; Lamarche, B.; Perusse, L.; Vohl, M.C. Familial resemblances in blood leukocyte DNA methylation levels. Epigenetics 2016, 11, 831-838. [CrossRef] [PubMed]

24. Tremblay, B.L.; Guenard, F.; Lamarche, B.; Perusse, L.; Vohl, M.C. Familial resemblances in human whole blood transcriptome. BMC Genom. 2018, 19, 300. [CrossRef] [PubMed]

25. Tremblay, B.L.; Guenard, F.; Lamarche, B.; Perusse, L.; Vohl, M.C. Familial resemblances in human plasma metabolites are attributable to both genetic and common environmental effects. Nutr. Res. 2019, 61, $22-30$. [CrossRef] [PubMed]

26. Callaway, C.; Chumlea, W.; Bouchard, C.; Himes, J.; Lohman, T.; Martin, A.; Mitchell, C.; Mueller, W.; Roche, A.; Seefeldt, V. Standardization of Anthropomeric Measurements: The Airlie (va) Consensus Conference; Human Kinetics: Champaign, IL, USA, 1988; pp. 39-80.

27. McNamara, J.R.; Schaefer, E.J. Automated enzymatic standardized lipid analyses for plasma and lipoprotein fractions. Clin. Chim. Acta 1987, 166, 1-8. [CrossRef]

28. Burstein, M.; Samaille, J. On a rapid determination of the cholesterol bound to the serum alpha- and beta-lipoproteins. Clin. Chim. Acta 1960, 5, 609. [CrossRef]

29. Albers, J.J.; Warnick, G.R.; Wiebe, D.; King, P.; Steiner, P.; Smith, L.; Breckenridge, C.; Chow, A.; Kuba, K.; Weidman, S.; et al. Multi-laboratory comparison of three heparin-mn2+ precipitation procedures for estimating cholesterol in high-density lipoprotein. Clin. Chem. 1978, 24, 853-856.

30. Friedewald, W.T.; Levy, R.I.; Fredrickson, D.S. Estimation of the concentration of low-density lipoprotein cholesterol in plasma, without use of the preparative ultracentrifuge. Clin. Chem. 1972, 18, 499-502. [PubMed]

31. Laurell, C.B. Quantitative estimation of proteins by electrophoresis in agarose gel containing antibodies. Anal. Biochem. 1966, 15, 45-52. [CrossRef]

32. Pirro, M.; Bergeron, J.; Dagenais, G.R.; Bernard, P.M.; Cantin, B.; Despres, J.P.; Lamarche, B. Age and duration of follow-up as modulators of the risk for ischemic heart disease associated with high plasma c-reactive protein levels in men. Arch. Intern. Med. 2001, 161, 2474-2480. [CrossRef] [PubMed]

33. Richterich, R.; Dauwalder, H. Determination of plasma glucose by hexokinase-glucose-6-phosphate dehydrogenase method. Schweizerische Medizinische Wochenschrift 1971, 101, 615-618. [PubMed]

34. Desbuquois, B.; Aurbach, G.D. Use of polyethylene glycol to separate free and antibody-bound peptide hormones in radioimmunoassays. J. Clin. Endocrinol. Metab. 1971, 33, 732-738. [CrossRef] [PubMed] 
35. Price, M.E.; Cotton, A.M.; Lam, L.L.; Farre, P.; Emberly, E.; Brown, C.J.; Robinson, W.P.; Kobor, M.S. Additional annotation enhances potential for biologically-relevant analysis of the illumina infinium humanmethylation450 beadchip array. Epigenet. Chromatin 2013, 6, 4. [CrossRef] [PubMed]

36. Team, R.C. R: A Language and Environment for Statistical Computing; R Foundation for Statistical Computing: Vienna, Austria, 2013.

37. Tremblay, B.L.; Guenard, F.; Lamarche, B.; Perusse, L.; Vohl, M.C. Weighted gene co-expression network analysis to explain the relationship between plasma total carotenoids and lipid profile. Genes Nutr. 2019, 14, 16. [CrossRef] [PubMed]

38. Langfelder, P.; Horvath, S. Fast R functions for robust correlations and hierarchical clustering. J. Stat. Softw. 2012, 46, 1-17. [CrossRef]

39. Zhang, B.; Horvath, S. A general framework for weighted gene co-expression network analysis. Stat. Appl. Genet. Mol. Biol. 2005, 4, 17. [CrossRef] [PubMed]

40. Langfelder, P.; Horvath, S. Eigengene networks for studying the relationships between co-expression modules. BMC Syst. Biol. 2007, 1, 54. [CrossRef] [PubMed]

41. Horvath, S.; Zhang, B.; Carlson, M.; Lu, K.V.; Zhu, S.; Felciano, R.M.; Laurance, M.F.; Zhao, W.; Qi, S.; Chen, Z.; et al. Analysis of oncogenic signaling networks in glioblastoma identifies aspm as a molecular target. Proc. Natl. Acad. Sci. USA 2006, 103, 17402-17407. [CrossRef] [PubMed]

42. Visant 5.0. Visual Analyses of Metabolic Networks in Cells and Ecosystems. Available online: http: //visant.bu.edu (accessed on 18 December 2018).

43. Hu, Z.; Snitkin, E.S.; DeLisi, C. Visant: An integrative framework for networks in systems biology. Brief. Bioinform. 2008, 9, 317-325. [CrossRef] [PubMed]

44. Kuleshov, M.V.; Jones, M.R.; Rouillard, A.D.; Fernandez, N.F.; Duan, Q.; Wang, Z.; Koplev, S.; Jenkins, S.L.; Jagodnik, K.M.; Lachmann, A.; et al. Enrichr: A comprehensive gene set enrichment analysis web server 2016 update. Nucleic Acids Res. 2016, 44, W90-W97. [CrossRef] [PubMed]

45. Borel, P.; Desmarchelier, C.; Nowicki, M.; Bott, R. A combination of single-nucleotide polymorphisms is associated with interindividual variability in dietary beta-carotene bioavailability in healthy men. J. Nutr. 2015, 145, 1740-1747. [CrossRef] [PubMed]

46. Borel, P.; Desmarchelier, C.; Nowicki, M.; Bott, R. Lycopene bioavailability is associated with a combination of genetic variants. Free Radic. Biol. Med. 2015, 83, 238-244. [CrossRef] [PubMed]

47. Borel, P.; Desmarchelier, C.; Nowicki, M.; Bott, R.; Morange, S.; Lesavre, N. Interindividual variability of lutein bioavailability in healthy men: Characterization, genetic variants involved, and relation with fasting plasma lutein concentration. Am. J. Clin. Nutr. 2014, 100, 168-175. [CrossRef]

48. Fu, L.J.; Ding, Y.B.; Wu, L.X.; Wen, C.J.; Qu, Q.; Zhang, X.; Zhou, H.H. The effects of lycopene on the methylation of the gstp1 promoter and global methylation in prostatic cancer cell lines pc3 and lncap. Int. J. Endocrinol. 2014, 2014, 620165. [CrossRef] [PubMed]

49. Yang, Y.; Fuentes, F.; Shu, L.; Wang, C.; Pung, D.; Li, W.; Zhang, C.; Guo, Y.; Kong, A.N. Epigenetic cpg methylation of the promoter and reactivation of the expression of gstp1 by astaxanthin in human prostate lncap cells. AAPS J. 2017, 19, 421-430. [CrossRef] [PubMed]

50. Willer, C.J.; Schmidt, E.M.; Sengupta, S.; Peloso, G.M.; Gustafsson, S.; Kanoni, S.; Ganna, A.; Chen, J.; Buchkovich, M.L.; Mora, S.; et al. Discovery and refinement of loci associated with lipid levels. Nat. Genet. 2013, 45, 1274-1283. [PubMed]

51. Ligthart, S.; Vaez, A.; Hsu, Y.H.; Inflammation Working Group of the CHARGE Consortium; PMI-WG-XCP; LifeLines Cohort Study; Stolk, R.; Uitterlinden, A.G.; Hofman, A.; Alizadeh, B.Z.; et al. Bivariate genome-wide association study identifies novel pleiotropic loci for lipids and inflammation. BMC Genom. 2016, 17, 443.

52. Huan, T.; Rong, J.; Liu, C.; Zhang, X.; Tanriverdi, K.; Joehanes, R.; Chen, B.H.; Murabito, J.M.; Yao, C.; Courchesne, P.; et al. Genome-wide identification of microrna expression quantitative trait loci. Nat. Commun. 2015, 6, 6601. [CrossRef] [PubMed]

53. Willer, C.J.; Sanna, S.; Jackson, A.U.; Scuteri, A.; Bonnycastle, L.L.; Clarke, R.; Heath, S.C.; Timpson, N.J.; Najjar, S.S.; Stringham, H.M.; et al. Newly identified loci that influence lipid concentrations and risk of coronary artery disease. Nat. Genet. 2008, 40, 161-169. [CrossRef] [PubMed]

54. Comuzzie, A.G.; Cole, S.A.; Laston, S.L.; Voruganti, V.S.; Haack, K.; Gibbs, R.A.; Butte, N.F. Novel genetic loci identified for the pathophysiology of childhood obesity in the hispanic population. PLoS ONE 2012, 7 , e51954. [CrossRef] [PubMed] 
55. Altunrende, M.E.; Gezen-Ak, D.; Atasoy, I.L.; Candas, E.; Dursun, E. The role of astaxanthin on transcriptional regulation of nmda receptors voltage sensitive calcium channels and calcium binding proteins in primary cortical neurons. Noro Psikiyatr. Ars. 2018, 55, 295-300. [CrossRef] [PubMed]

56. Notarangelo, L.D.; Kim, M.S.; Walter, J.E.; Lee, Y.N. Human rag mutations: Biochemistry and clinical implications. Nat. Rev. Immunol. 2016, 16, 234-246. [CrossRef] [PubMed]

57. Reardon, C.A.; Blachowicz, L.; White, T.; Cabana, V.; Wang, Y.; Lukens, J.; Bluestone, J.; Getz, G.S. Effect of immune deficiency on lipoproteins and atherosclerosis in male apolipoprotein e-deficient mice. Arterioscler. Thromb. Vasc. Biol. 2001, 21, 1011-1016. [CrossRef] [PubMed]

58. Hall, A.M.; Krishnamoorthy, L.; Orlow, S.J. 25-hydroxycholesterol acts in the golgi compartment to induce degradation of tyrosinase. Pigment Cell Res. 2004, 17, 396-406. [CrossRef] [PubMed]

59. Hoffmann, T.J.; Theusch, E.; Haldar, T.; Ranatunga, D.K.; Jorgenson, E.; Medina, M.W.; Kvale, M.N.; Kwok, P.Y.; Schaefer, C.; Krauss, R.M.; et al. A large electronic-health-record-based genome-wide study of serum lipids. Nat. Genet. 2018, 50, 401-413. [CrossRef] [PubMed]

60. Kaess, B.M.; Tomaszewski, M.; Braund, P.S.; Stark, K.; Rafelt, S.; Fischer, M.; Hardwick, R.; Nelson, C.P.; Debiec, R.; Huber, F.; et al. Large-scale candidate gene analysis of hdl particle features. PLoS ONE 2011, 6, e14529. [CrossRef]

61. Simmen, T.; Aslan, J.E.; Blagoveshchenskaya, A.D.; Thomas, L.; Wan, L.; Xiang, Y.; Feliciangeli, S.F.; Hung, C.H.; Crump, C.M.; Thomas, G. Pacs-2 controls endoplasmic reticulum-mitochondria communication and bid-mediated apoptosis. EMBO J. 2005, 24, 717-729. [CrossRef]

62. Yang, R.Y.; Hsu, D.K.; Yu, L.; Chen, H.Y.; Liu, F.T. Galectin-12 is required for adipogenic signaling and adipocyte differentiation. J. Biol. Chem. 2004, 279, 29761-29766. [CrossRef]

63. The Coronary Artery Disease (C4D) Genetics Consortium. A genome-wide association study in europeans and south asians identifies five new loci for coronary artery disease. Nat. Genet. 2011, 43, 339-344. [CrossRef]

64. Dichgans, M.; Malik, R.; Konig, I.R.; Rosand, J.; Clarke, R.; Gretarsdottir, S.; Thorleifsson, G.; Mitchell, B.D.; Assimes, T.L.; Levi, C.; et al. Shared genetic susceptibility to ischemic stroke and coronary artery disease: A genome-wide analysis of common variants. Stroke 2014, 45, 24-36. [CrossRef] [PubMed]

65. Wain, L.V.; Verwoert, G.C.; O’Reilly, P.F.; Shi, G.; Johnson, T.; Johnson, A.D.; Bochud, M.; Rice, K.M.; Henneman, P.; Smith, A.V.; et al. Genome-wide association study identifies six new loci influencing pulse pressure and mean arterial pressure. Nat. Genet. 2011, 43, 1005-1011. [CrossRef] [PubMed]

66. Guénard, F.; Deshaies, Y.; Hould, F.S.; Lebel, S.; Tchernof, A.; Marceau, P.; Vohl, M.C. Use of blood as a surrogate model for the assessment of visceral adipose tissue methylation profiles associated with the metabolic syndrome in men. J. Mol. Genet. Med. 2016, 10. [CrossRef]

67. Gruber, M.; Chappell, R.; Millen, A.; LaRowe, T.; Moeller, S.M.; Iannaccone, A.; Kritchevsky, S.B.; Mares, J. Correlates of serum lutein + zeaxanthin: Findings from the third national health and nutrition examination survey. J. Nutr. 2004, 134, 2387-2394. [CrossRef] [PubMed]

68. Al-Delaimy, W.K.; van Kappel, A.L.; Ferrari, P.; Slimani, N.; Steghens, J.P.; Bingham, S.; Johansson, I.; Wallstrom, P.; Overvad, K.; Tjonneland, A.; et al. Plasma levels of six carotenoids in nine European countries: Report from the European prospective investigation into cancer and nutrition (epic). Public Health Nutr. 2004, 7, 713-722. [CrossRef] [PubMed]

(C) 2019 by the authors. Licensee MDPI, Basel, Switzerland. This article is an open access article distributed under the terms and conditions of the Creative Commons Attribution (CC BY) license (http://creativecommons.org/licenses/by/4.0/). 